Yongjin Guo

Luyun Chen

Hongdong Wang

Hong Yi

http://dx.doi.org/10.21278/brod70202

ISSN 0007-215X

eISSN 1845-5859

\title{
EXPERIMENTAL STUDY OF WELDING RESIDUAL STRESS OF HIGH-STRENGTH SHIPBUILDING STEEL
}

UDC 691.714:52-334.2

Professional paper

\begin{abstract}
Summary
Ships are large welded structures. Welding residual stress (WRS) significantly impacts the mechanical properties of the structure. The plate and cylinder models welded by electrode welding (EW) and submerged arc welding (SAW) were designed to measure the WRS of high-strength shipbuilding steel. The WRS was tested by instrumented indentation method. The stress value of each measure point was proposed. The stress distribution patterns of different welding processes and models were analysed. This research can provide a reference for controlling the WRS of ships and improving shipbuilding quality.
\end{abstract}

Key words: high-strength shipbuilding steel; welding residual stress; instrument indentation test

\section{Introduction}

High-strength steel has favourable mechanical properties and is widely used in manufacturing ship structures $[1,2]$. Under the same structural strength, using high-strength steel can reduce hull weight, increase carrying capacity and reduce operating cost slightly. Many structural parts of ships are welded by high-strength steel plates. Uneven heating during the welding process will cause local plastic deformation of the weldment, thereby resulting in WRS in the structure, which poses a potential threat to the safety of the structure and adversely affects the fabrication, performance, and service life of ships [3-7]. High-strength steel material is added to alloying elements on the basis of ordinary-strength steel, and its welding performance is different from that of ordinary-strength steel. Therefore, the WRS of high-strength shipbuilding steel must be explored to improve the construction quality and performance of ships.

Many studies have been conducted on the numerical simulation and measurement of WRS. Perić et al. [8] investigated the welding distortion in a T-joint fillet weld using an experimental method and finite element simulations, thereby verifying that 3D technology is an effective method for predicting welding distortions and residual stresses for large structures. The features of the WRS distribution near a weld end-start location have been 
investigated through experiment and numerical simulation [9]. Deng and Murakawa [10] used large and small deformation theories to simulate WRS and deformation in a butt-welded joint. Deng et al. [11] used numerical simulation technology and experimental method to investigate the characteristics of WRS distribution in several typical welded joints, which are used in nuclear power plants. The WRS of the lap joints of thin steel sheets was measured by $\mathrm{X}$-ray diffraction method and compared with the numerical simulation, thus confirming that the WRSs in the arc-welded lap joints are significantly influenced by the strength of the base metal and welding heat input [12]. Zhao et al. [13] applied finite element method to calculate the WRS for Invar steel of an LNG carrier containment system, whereas the x-ray diffraction method was applied to measure the longitudinal WRS of the welding joint. The research concluded that the effect of WRS cannot be neglected when the fatigue life of the LNG carrier containment system is assessed under a sloshing impact.

Several researchers have studied the influence of different welding processes on WRS. An X-ray diffraction technique was used to measure the surface residual stress distribution of high-strength steel by hybrid laser/gas metal arc welding in a butt joint configuration. The influence of welding parameters, including welding speed and wire feeding rate, on the residual stress distribution and mechanical properties of a hybrid weld has been experimentally studied [14]. Chen et al. [15] simulated six welding sequences to study their influence on the WRS of a stiffened plate structure. Kong and Kovacevic [16] confirmed that the residual stress concentration in the welded joint obtained by a hybrid laser-gas tungsten arc welding is smaller than when using laser welding alone. The surface residual stress evaluation for double-electrode welding has been studied [17]. The residual stress generated by the double-electrode welding is generally higher than that by single-electrode welding. Fu et al. [18] investigated the WRS and distortion in T-joint welds under various mechanical boundary conditions. The effects of preheating, interpass and transient-releasing temperatures on the residual stresses in the multipass welding of high-strength shipbuilding steel are investigated [19].

In general, WRS is a research hotspot in the field of materials and manufacturing. However, currently there are few measuring data for WRS of high-strength shipbuilding steel under the actual welding process. In order to solve this problem, we create the plate and cylinder models under the processes of EW and automatic SAW to measure the WRS distributions by the instrumented indentation method. The measuring data may contribute to conduct the analysis of mechanical properties of ship structures and quantitative calculation of WRS in shipbuilding. Meanwhile, this study can provide a reference for controlling the WRS of ships and improving the shipbuilding quality.

\section{Measurement method of the WRS}

In this research, instrument indentation method was adopted to measure the WRS. In Fig. 1, the principle of this method is that the indentation force required to reach a given depth $\left(h_{m}\right)$ under residual stress is different from that in the stress-free state [20]. The slope of forcedepth curve is changed by tensile residual stress $\left(F_{\mathrm{T}}\right)$ or compressive residual stress $\left(F_{\mathrm{C}}\right)$ in a target test piece. 

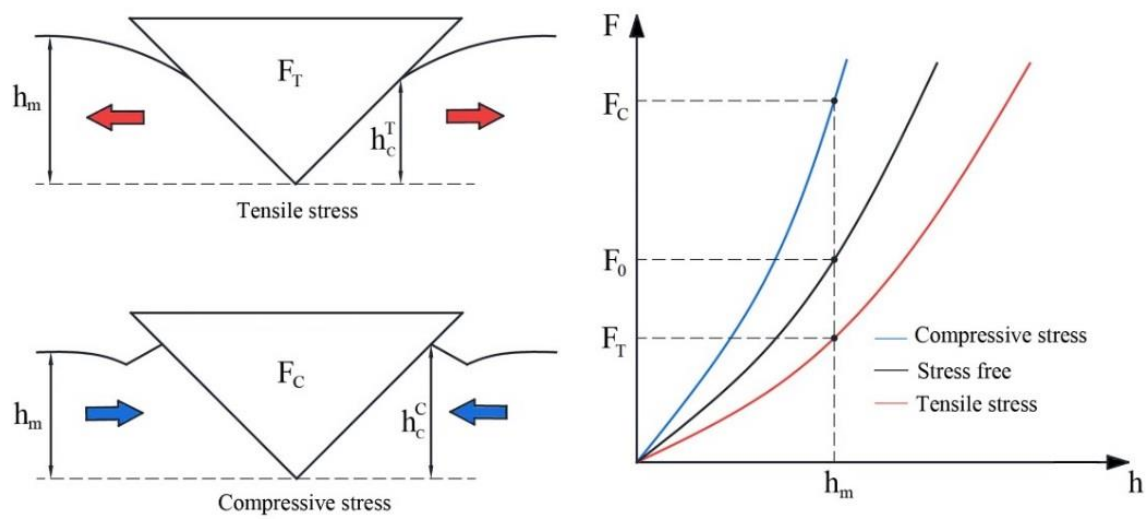

Fig. 1 Principle of instrument indentation method

From the stressed and stress-free force-depth curves, the force difference between two curves can be calculated at a given indentation depth. The force difference can be correlated to residual stress by considering the stress state under the indenter tip. Only surface biaxial stresses can affect the shape of the force-depth curve [21, 22]. Biaxial stresses can be divided into mean stress (hydrostatic stress) and plastic-deformation-sensitive shear deviator stress terms described in Eq. (1) [23, 24].

$$
\left(\begin{array}{ccc}
\sigma_{\text {res }} & 0 & 0 \\
0 & p \sigma_{\text {res }} & 0 \\
0 & 0 & 0
\end{array}\right)=\left(\begin{array}{ccc}
\frac{(1+p)}{3} \sigma_{\text {res }} & 0 & 0 \\
0 & \frac{(1+p)}{3} \sigma_{\text {res }} & 0 \\
0 & 0 & \frac{(1+p)}{3} \sigma_{r e s}
\end{array}\right)+\left(\begin{array}{ccc}
\frac{(2-p)}{3} \sigma_{r e s} & 0 & 0 \\
0 & \frac{(2 p-1)}{3} \sigma_{r e s} & 0 \\
0 & 0 & -\frac{(1+p)}{3} \sigma_{\text {res }}
\end{array}\right)
$$

where $\sigma_{\text {res }}$ is the residual stress, and $p$ is the ratio of residual stresses along one direction to those along the normal direction, which can be determined by the indentation tests performed with a Knoop indenter. For welded steel joints, the value of $p$ is recommended as 1/3.

The indentation test direction is defined as $z$, Only the shear deviatoric stress component applied along the indentation test direction $\left(\sigma_{z, d}\right)$ can influence the force-depth curve, and $\sigma_{z, d}$ can be related to the force difference:

$$
\begin{gathered}
\sigma_{z, d}=\frac{(1+p)}{3} \sigma_{r e s}=\frac{1}{\psi} \frac{\left(F-F_{T}\right)}{A} \\
\sigma_{z, d}=\frac{(1+p)}{3} \sigma_{r e s}=\frac{1}{\psi} \frac{\left(F-F_{C}\right)}{A}
\end{gathered}
$$

where $\sigma_{z, d}$ is the shear deviatoric stress component applied along the indentation test direction, $F$ is the test force, $\psi$ is the ratio of average contact pressure to true stress and $A$ is the contact area including residual stress.

From the relationship in which $\sigma_{\text {res }}$ is proportional to the indentation force difference, the residual stress for tensile and compressive residual stresses can be expressed as follows:

$$
\sigma_{r e s}=\frac{1}{\psi} \frac{3}{(1+p)} \frac{\left(F-F_{T}\right)}{A}
$$




$$
\sigma_{r e s}=\frac{1}{\psi} \frac{3}{(1+p)} \frac{\left(F-F_{C}\right)}{A}
$$

The measurement method is easy to execute and has high measurement accuracy and speed. This method has reached a micro destructive level and can test the residual stress of a large gradient change. In addition, the test equipment is convenient and suitable for a shipyard, which has a high application value in shipbuilding.

\section{Experimental scheme}

\subsection{Experimental material and welding process}

The material of the base metal is high-strength low-alloy $10 \mathrm{CrNi} 3 \mathrm{MoV}$ steel, which is a reliable material for the key components in shipbuilding due to its superior mechanical properties and good weldability. The chemical composition and mechanical properties of the material are summarised in Tables 1 and 2.

Table 1 Chemical composition of the base steel

\begin{tabular}{|c|c|c|c|c|c|c|c|c|c|c|}
\hline Steel & $\mathrm{C}$ & $\mathrm{Si}$ & $\mathrm{Mn}$ & $\mathrm{Cr}$ & $\mathrm{Mo}$ & $\mathrm{Ni}$ & $\mathrm{Cu}$ & $\mathrm{V}$ & $\mathrm{S}$ & $\mathrm{P}$ \\
\hline 10CrNi3MoV & 0.09 & 0.29 & 0.48 & 0.94 & 0.4 & 2.88 & - & 0.06 & 0.005 & 0.011 \\
\hline
\end{tabular}

Table 2 Mechanical properties of the base steel

\begin{tabular}{|c|c|c|c|c|c|}
\hline Thickness & $\begin{array}{c}\text { Elasticity } \\
\text { modulus/Mpa }\end{array}$ & Poisson ratio & Yield stress/Mpa & Elongation/\% & $\begin{array}{c}\text { Reduction } \\
\text { of area/\% }\end{array}$ \\
\hline $14 \mathrm{~mm}$ & $2.1 \times 10^{5}$ & 0.3 & 590 & $>16$ & $>10$ \\
\hline
\end{tabular}

The low carbon content of the steel material ensures favourable weldability. The addition of $\mathrm{Ni}$ increases the toughness and plasticity of the steel and reduces the brittle transition temperature. The hardenability of steel is improved by adding appropriate $\mathrm{Cr}$ and $\mathrm{Ni}$ elements. Other alloy elements, such as Mn, Mo and V, ensure the favourable comprehensive mechanical properties of the material. The welding processes used in the experiment are EW and SAW. The automation degree is higher in SAW than in EW. SAW has a better welding quality and repeatability than EW. The main drawback of the SAW is that the parts of complex products cannot be easily welded because the welding head is difficult to retract in place. The EW equipment is low cost with favourable flexibility and conveniences. However, this equipment requires a high-operation technique for welders, and the quality stability of the weld is inferior. These welding methods are commonly used in the welding of ship structures.

The experimental models were welded in accordance with the specific welding process proposed by Zhao [25]. The double-v groove was created. The welding current of the SAW is $500 \mathrm{~A}$, with the welding speed of $35 \mathrm{~cm} / \mathrm{min}$. The welding current of EW is 150 A. Table 3 lists the chemical composition of the welding rods.

Table 3 Chemical composition of the welding rods

\begin{tabular}{|c|c|c|}
\hline Welding process & SAW & EW \\
\hline $\mathrm{C}$ & $0.055 \sim 0.095$ & $\leq 0.04$ \\
\hline $\mathrm{Si}$ & $\leq 0.03$ & $\leq 0.12$ \\
\hline $\mathrm{Mn}$ & $1.75 \sim 2.10$ & $1.05 \sim 1.45$ \\
\hline $\mathrm{Cr}$ & $\leq 0.20$ & $0.10 \sim 0.24$ \\
\hline $\mathrm{Mo}$ & $0.20 \sim 0.40$ & $0.10 \sim 0.24$ \\
\hline $\mathrm{Ni}$ & $2.20 \sim 2.50$ & $3.10 \sim 3.40$ \\
\hline $\mathrm{V}$ & $0.04 \sim 0.10$ & - \\
\hline $\mathrm{Ti}$ & $0.05 \sim 0.15$ & - \\
\hline $\mathrm{S}$ & $\leq 0.01$ & $\leq 0.015$ \\
\hline $\mathrm{P}$ & $\leq 0.01$ & $\leq 0.018$ \\
\hline
\end{tabular}




\subsection{Experimental model}

(1) Model 1 is a steel plate that was welded by two identical plates using EW. As shown in Fig. 2, the length, width and thickness of the model are 1200, 800 and $14 \mathrm{~mm}$, correspondingly. The weld bead is at the centre of the long side. Three measuring lines, labelled with Lines A, B and C, were designed on the top side of the plate. Three measuring lines, labelled with Lines A', B' and C', were designed on the backside of the plate. Measuring lines $\mathrm{A}$ and $\mathrm{A}^{\prime}$ have 20 measuring points, and the other lines have 10 measuring points.

(a)

(b)
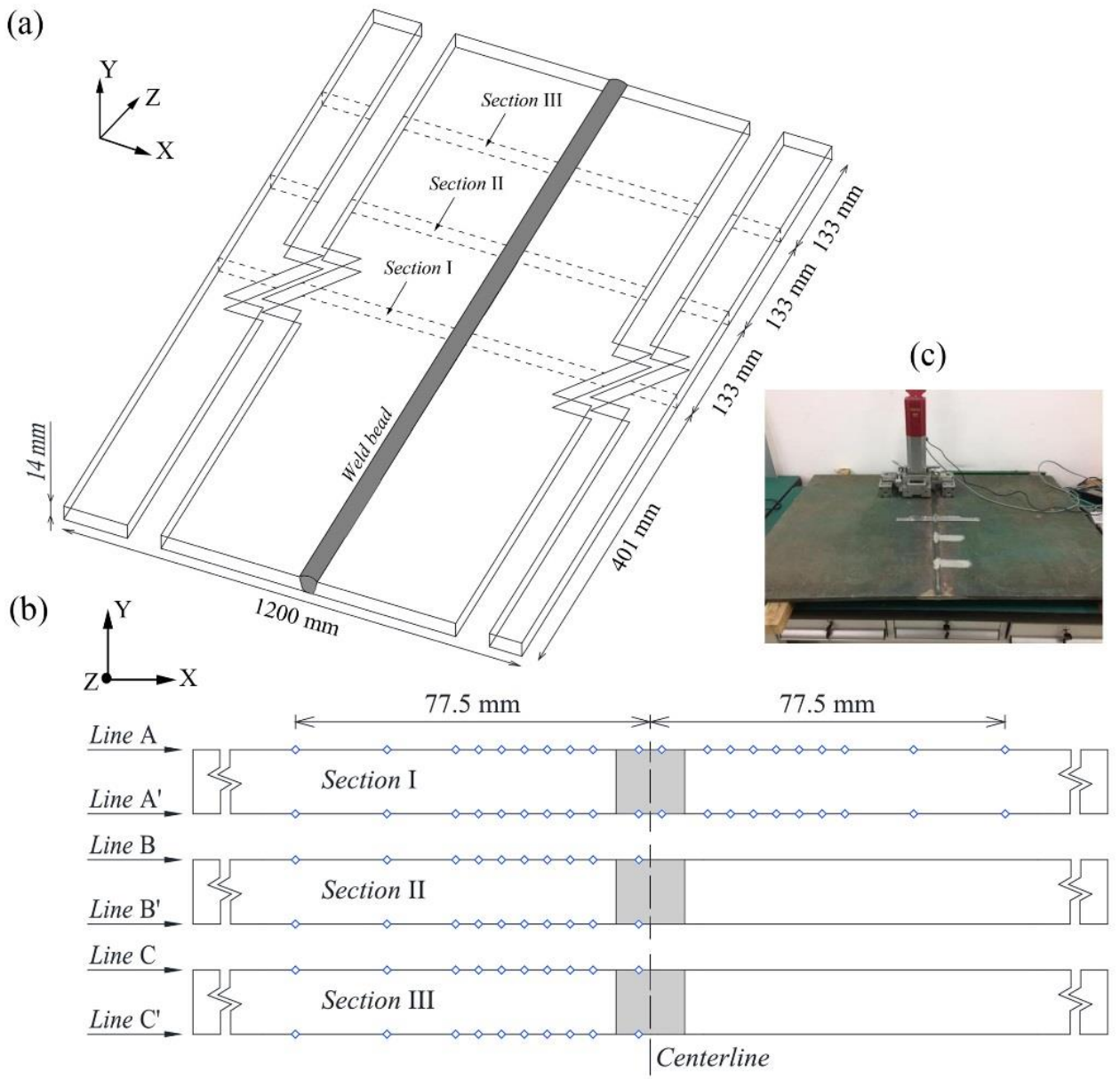

Fig. 2 Measurement model of a steel plate (a). Arrangement of measuring points (b).

WRS measurement (c)

(2) Model 2 is a steel plate that was welded by two identical plates using the SAW. Its geometric dimensions and the location of weld bead are the same as those of Model 1. Three measuring lines, labelled with Lines D, E and F, were designed on the top side of the plate. Three measuring lines, labelled with Lines D', E' and F', were designed on the backside of the plate. Measuring lines D and D' have 20 measuring points, and the other lines have 10 measuring points.

(3) Model 3 is a steel cylinder with length, inner diameter and outer diameter of 200, 336 and $350 \mathrm{~mm}$. The centre of the model has two weld beads. The circumferential weld bead was welded by EW, and the axial one was welded by the SAW. Three measuring lines, labelled with Lines G, H and I, were designed for the axial weld. Line $\mathrm{G}$ has 20 measuring points, and the $\mathrm{H}$ and $\mathrm{I}$ have 10 measuring points. Two measuring lines were set for circumferential weld with Measuring lines $\mathrm{J}$ and $\mathrm{K}$. Each line has 20 measuring points. The size and point layout of the model are illustrated in Fig. 3. 
(a)

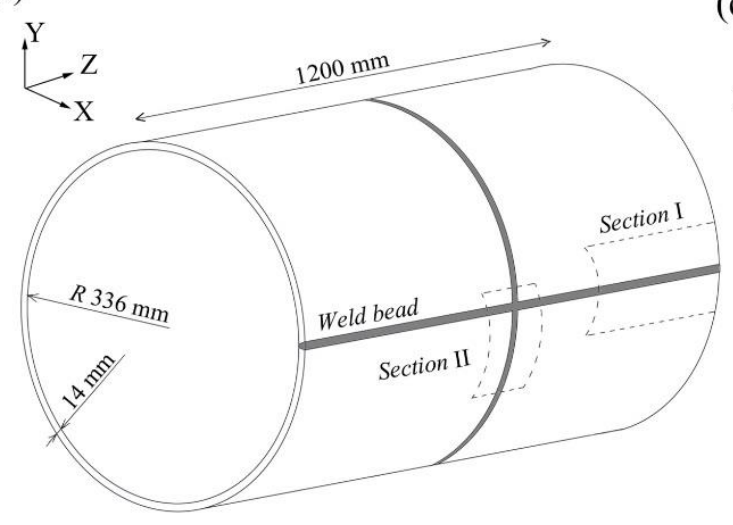

(b)

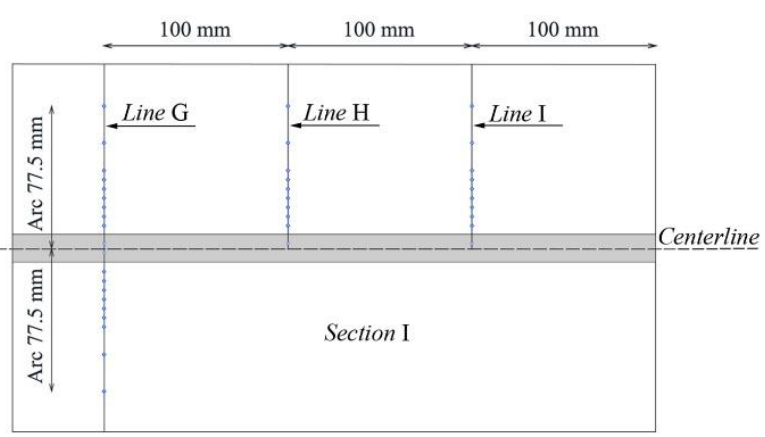

(c)

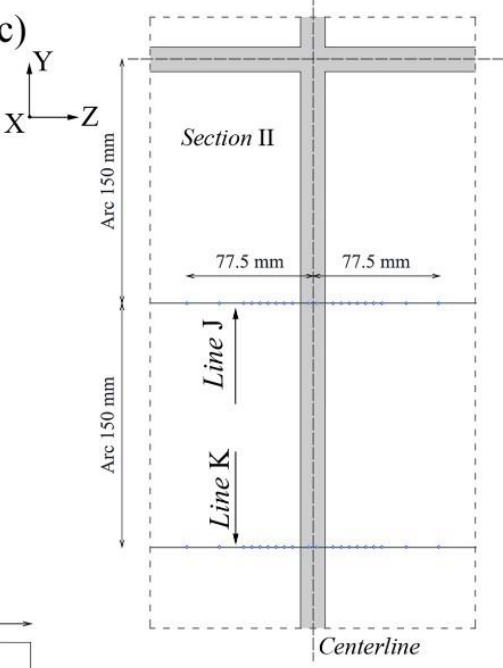

(d)

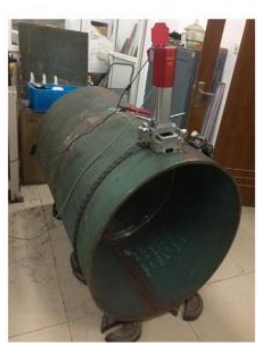

Fig. 3 Measurement model of a cylinder (a). Arrangement of the measuring points of Section I (b). Arrangement of the measuring points of Section II (c). WRS measurement (d)

\subsection{Experimental procedure}

According to the instrumented indentation measurement scheme, the experimental procedure is presented as follows:

- Selection of measuring area

- Selection of the base material area

- Grinding of the measuring area

- Arrangement and marking of measuring points

- Installation and fixing of indentation testers

- Indentation measurement of the base material using a spherical indenter

- Indentation measurement of the measurement area using a spherical indenter.

- Indentation measurement of the measurement area using Vickers indenter

- Data processing and analysis

\section{Experimental scheme}

The results of Models 1, 2 and 3 are listed in Tables 4, 5 and 6, respectively. 
Table 4 WRS of the plate by EW

\begin{tabular}{|c|c|c|c|c|c|c|}
\hline \multirow{2}{*}{$\begin{array}{c}\text { Distance from } \\
\text { centerline / mm }\end{array}$} & \multicolumn{7}{|c|}{ Residual stress / Mpa } \\
\hline-77.5 & 119.46 & -112.17 & 240.59 & 86.81 & 168.82 & 29.92 \\
\hline-57.5 & 103.11 & -346.43 & -177.31 & -15.21 & 216.99 & -41.71 \\
\hline-42.5 & 105.68 & -249.56 & -56.47 & 112.56 & 63.56 & 13.59 \\
\hline-37.5 & 3.75 & -25.04 & 43.32 & -0.09 & 78.63 & -6.32 \\
\hline-32.5 & 50.66 & -121.02 & 106.17 & 25.99 & 32.39 & -12.83 \\
\hline-27.5 & 87.65 & -68.5 & 17.93 & 74.67 & 183.45 & -14.05 \\
\hline-22.5 & 101.75 & -119.17 & 3.91 & 25.83 & 314.37 & 13.05 \\
\hline-17.5 & 17.13 & -64.29 & 87.84 & 43.74 & 133.49 & -48.65 \\
\hline-12.5 & 91.87 & -66.28 & 79.84 & 75.63 & 167.86 & -2.76 \\
\hline-2.5 & 352.97 & -53.94 & 118.41 & -17 & 611.29 & 300.69 \\
\hline 2.5 & 81.77 & 277.2 & - & - & - & - \\
\hline 12.5 & 25.53 & 56.5 & - & - & - & - \\
\hline 17.5 & 188.51 & -29.41 & - & - & - & - \\
\hline 22.5 & 125.81 & -85.44 & - & - & - & - \\
\hline 27.5 & -69.25 & -51.08 & - & - & - & - \\
\hline 32.5 & 34.24 & -0.9 & - & - & - & - \\
\hline 37.5 & 60.29 & -180.03 & - & - & - & - \\
\hline 42.5 & 37.61 & -87.55 & - & - & - & - \\
\hline 57.5 & -14.53 & -64.72 & - & - & - & - \\
\hline 77.5 & 51.99 & -153.3 & - & - & - & - \\
\hline & & & & & & \\
\hline
\end{tabular}

Table 5 WRS of the plate by SAW

\begin{tabular}{|c|c|c|c|c|c|c|}
\hline \multirow{2}{*}{$\begin{array}{c}\text { Distance from } \\
\text { centerline / mm }\end{array}$} & \multicolumn{7}{|c|}{ Residual stress / Mpa } \\
\cline { 2 - 7 } & Line D & Line D' & Line E & Line E' & Line F & Line F' $^{\prime}$ \\
\hline-77.5 & -26.22 & -98.74 & 4.95 & -56.03 & 8.9 & 28.7 \\
\hline-57.5 & 42.48 & -29.61 & -46.21 & -34.18 & -3.3 & 34.15 \\
\hline-42.5 & 43.75 & -52.56 & 39.67 & -24.6 & 42.6 & -58.32 \\
\hline-37.5 & 63.73 & -60.89 & -43.15 & 15.1 & -13.76 & -18.33 \\
\hline-32.5 & -10.85 & -23.39 & 67.53 & -19.91 & 62.5 & -73 \\
\hline-27.5 & 10.9 & -32.47 & 10.86 & -19.59 & 29.23 & -78.93 \\
\hline-22.5 & 59.36 & -48.15 & 53.88 & 1.85 & 20.96 & -38.53 \\
\hline-17.5 & 40.15 & -33.96 & -35.27 & -32.97 & 39.52 & -81.32 \\
\hline-12.5 & -34.23 & -94.06 & -50.47 & -20.71 & -11.48 & 106.27 \\
\hline-2.5 & 142.29 & 92.98 & 186.98 & 107.98 & 160.97 & 177.45 \\
\hline 2.5 & 155.8 & 112.36 & - & - & - & - \\
\hline 12.5 & -21.29 & -53.73 & - & - & - & - \\
\hline 17.5 & -35.47 & 30.46 & - & - & - & - \\
\hline 22.5 & -51.95 & 48.32 & - & - & - & - \\
\hline 27.5 & -27.69 & 13.73 & - & - & - & - \\
\hline 32.5 & 62.61 & -11.65 & - & - & - & - \\
\hline 37.5 & 35.81 & -32.26 & - & - & - & - \\
\hline 42.5 & 72.37 & -49.82 & - & - & - & - \\
\hline 57.5 & 80.42 & -14.97 & - & - & - & - \\
\hline 77.5 & 75.02 & -13.86 & - & - & - & - \\
\hline & & & & & \\
\hline
\end{tabular}


Table 6 WRS of the cylinder

\begin{tabular}{|c|c|c|c|c|c|}
\hline \multirow{2}{*}{$\begin{array}{c}\text { Distance from } \\
\text { centerline / mm }\end{array}$} & \multicolumn{5}{|c|}{ Residual stress / Mpa } \\
\cline { 2 - 6 } & Line G & Line H & Line I & Line J & Line K \\
\hline-77.5 & -76.89 & -29.28 & 28.7 & 80.03 & 105.88 \\
\hline-57.5 & -125.96 & 17.68 & 34.15 & 88.47 & 68.23 \\
\hline-42.5 & -111.26 & -43.8 & -58.32 & 91.86 & -33.02 \\
\hline-37.5 & -124.99 & -23.65 & -18.33 & 13.67 & 29.98 \\
\hline-32.5 & -133.52 & -78.71 & -73 & 26.26 & 27.37 \\
\hline-27.5 & -120.02 & -87.99 & -78.93 & 26.71 & 19.63 \\
\hline-22.5 & -73.91 & -17.69 & -38.53 & -57 & 43.27 \\
\hline-17.5 & -90.74 & -31.52 & -81.32 & -14.38 & -71.53 \\
\hline-12.5 & 126.3 & 165.93 & 106.27 & 44.87 & -39.76 \\
\hline-2.5 & 201.96 & 182.99 & 177.45 & 91.92 & -67.33 \\
\hline 2.5 & 98.98 & 265.78 & 172.46 & - & - \\
\hline 12.5 & 94.98 & - & - & 135.65 & 203.07 \\
\hline 17.5 & -34.04 & - & - & 73.14 & 100.83 \\
\hline 22.5 & -61.45 & - & - & 53.27 & 32.87 \\
\hline 27.5 & -54.69 & - & - & -9.68 & 38.36 \\
\hline 32.5 & 32.09 & - & - & -17.95 & -2.24 \\
\hline 37.5 & -10.41 & - & - & -58.22 & 39.44 \\
\hline 42.5 & -48.64 & - & - & -38.19 & 0.39 \\
\hline 57.5 & -12.38 & - & - & -33.37 & -89.32 \\
\hline 77.5 & 23 & - & - & -17.25 & -35.82 \\
\hline & & & & & \\
\hline
\end{tabular}

\section{Discussion}

\subsection{Maximum and minimum WRS}

Fig. 4 depicts the maximum residual tensile stress and residual compressive stress for each measuring line. The peak value of the tensile stress of most measuring lines is approximately $200 \mathrm{Mpa}$, and the maximum value exceeds $600 \mathrm{Mpa}$. Most of the residual compressive stress peaks are approximately $-100 \mathrm{Mpa}$, and the maximum compressive stress exceeds $-300 \mathrm{Mpa}$. Line $\mathrm{C}$ has no measured compressive stress value. The maximum tensile stress appears at $-2.5 \mathrm{~mm}$ from the centreline of Line $\mathrm{C}$, thereby exceeding the yield limit of the material. The condition can be attributed to two possible reasons. Firstly, the measured value may be the longitudinal residual stress of the weld bead. The mechanism is that the longitudinal shrinkage of the weld is constrained, and the longitudinal residual tensile stress exists in a narrow area near the weld. The value decreases with the increase in distance from the centreline. When no phase change occurs, the maximum value will reach or exceed the yield limit of the material. Secondly, the mechanical properties of the material during the welding heat process change with the increase or decrease in temperature, thereby directly affecting welding thermoplasticity, stress-strain process and magnitude of residual stress. The peak tensile stress in low carbon steel may approach the yield strength of the material. 


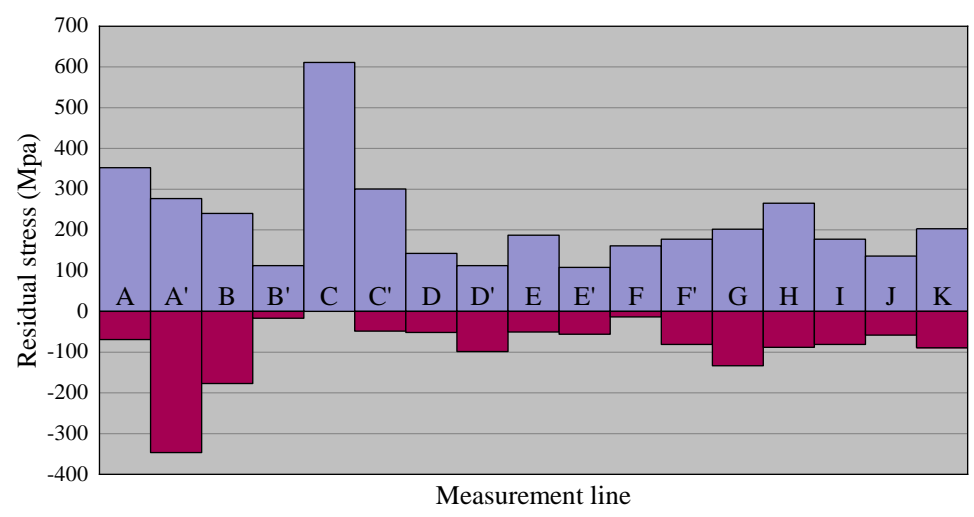

Fig. 4 Extreme WRS of each measuring line

\subsection{Distribution characteristics of WRS}

Fig. 5 demonstrates the results of Measuring lines A and D of the steel plates. The WRSs of the two lines vary with the distance from the centreline of the weld. The tensile stress appears near the centre section of the weld, and the peak values of the tensile stresses of the two lines are close to the centreline. This is due to the local heating of the heat source causes the thermal expansion of the joint and the surrounding area, thus resulting in compressive plastic deformation. When heat source arrives, the deformation reaches the maximum. The weld metal will crystallise, solidify and shrink whilst the heat source leaves. After welding, the residual stress will be tensile near the welding area. The peak value of Line $\mathrm{A}$ is $60 \%$ of the yield strength of the material; this value is $25 \%$ of Line D. A high tensile stress zone can easily cause cold cracks near the weld bead which depends on combining the basic welding metal and welding rods, as well as the process parameters. The residual stress decreases and stabilises with the increase in the distance between the measuring points and the centreline. The WRS distribution of the two lines is not completely symmetrical. The reason for which is related to the model parameters, welding process and measurement error.

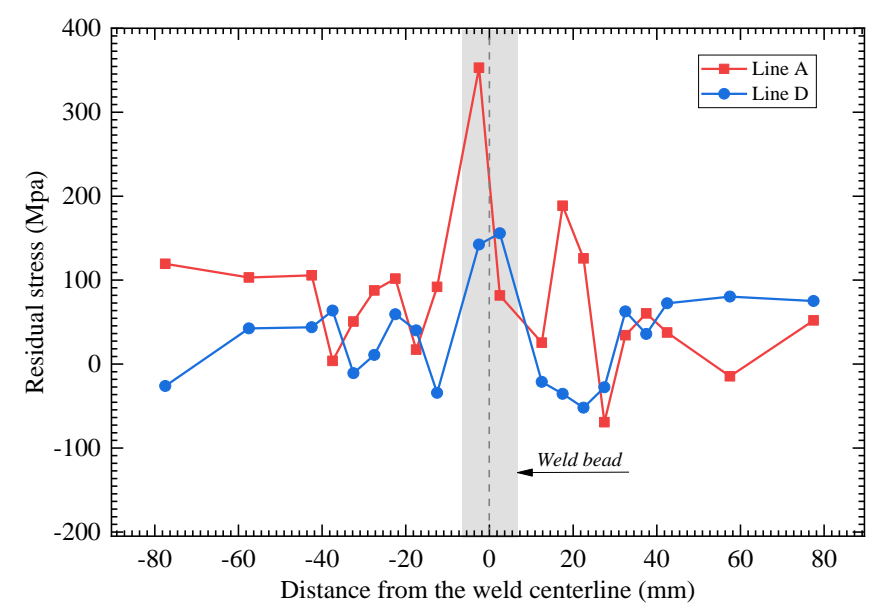

Fig. 5 WRS distribution of Measuring lines A and D

Fig. 6 exhibits the results of longitudinal weld Measuring line $\mathrm{G}$ and circumferential weld Measuring lines $\mathrm{J}$ and $\mathrm{K}$ of the cylinder. The stress peak also appears in the area that surrounds the weld. The peaks of Measuring lines $\mathrm{G}$ and $\mathrm{J}$ are approximately $35 \%$ of the yield strength and that of Line $\mathrm{K}$ is approximately $20 \%$. The residual stress distribution of Lines $\mathrm{G}$ and $\mathrm{K}$ is steep, thereby resulting in a large gradient residual stress. This result is due to welding is an abnormal local thermal process, accompanied by a highly nonlinear process of deformation. The high-temperature zone centred on the welding point is formed 
instantaneously, but the low-temperature zone may exist close to the peak of high temperature. A large temperature gradient exists between the two temperature zones, thus generating a large plastic strain gradient in the weld zone. Then, a large gradient residual stress will be generated around the weld zone.

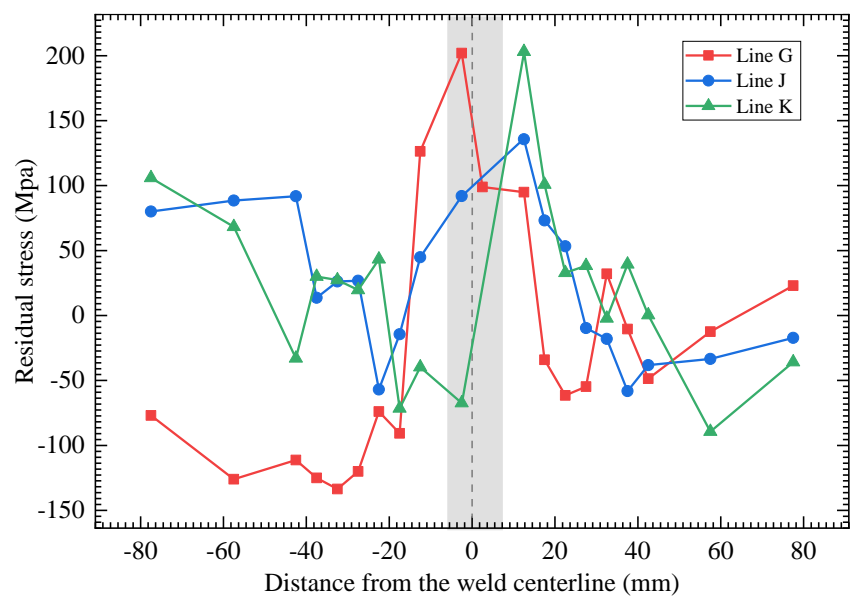

Fig. 6 WRS distribution of Measuring lines G, J and K

\subsection{Effect of welding processes}

Fig. 7 displays that the residual stress curve of EW fluctuates considerably, and the condition of Measuring lines A', B and B' is obvious. Several extreme points can be observed, whilst the maximum tensile stress does not appear at the weld. The stress distribution of EW is irregular. The residual stress curve of the SAW is relatively stable, and the residual stress curve generally decreases with the increase in distance from the weld. The maximum tensile stress appears at the weld, that is, $-2.5 \mathrm{~mm}$ from the centreline because EW is a manual operation whose process parameters are difficult to control. Residual stress is related to various factors, such as angle of welding, temperature and length-of-stay time at the same position. A relatively irregular distribution form is generated. The process parameters of the SAW are constant, thus resulting in a regular residual stress distribution. The stress amplitude of the EW varies significantly, whereas the amplitude of the SAW is small. The maximum values of tensile and compressive stresses appear through the $\mathrm{EW}$, which generates large energy input in several areas during the welding process. 

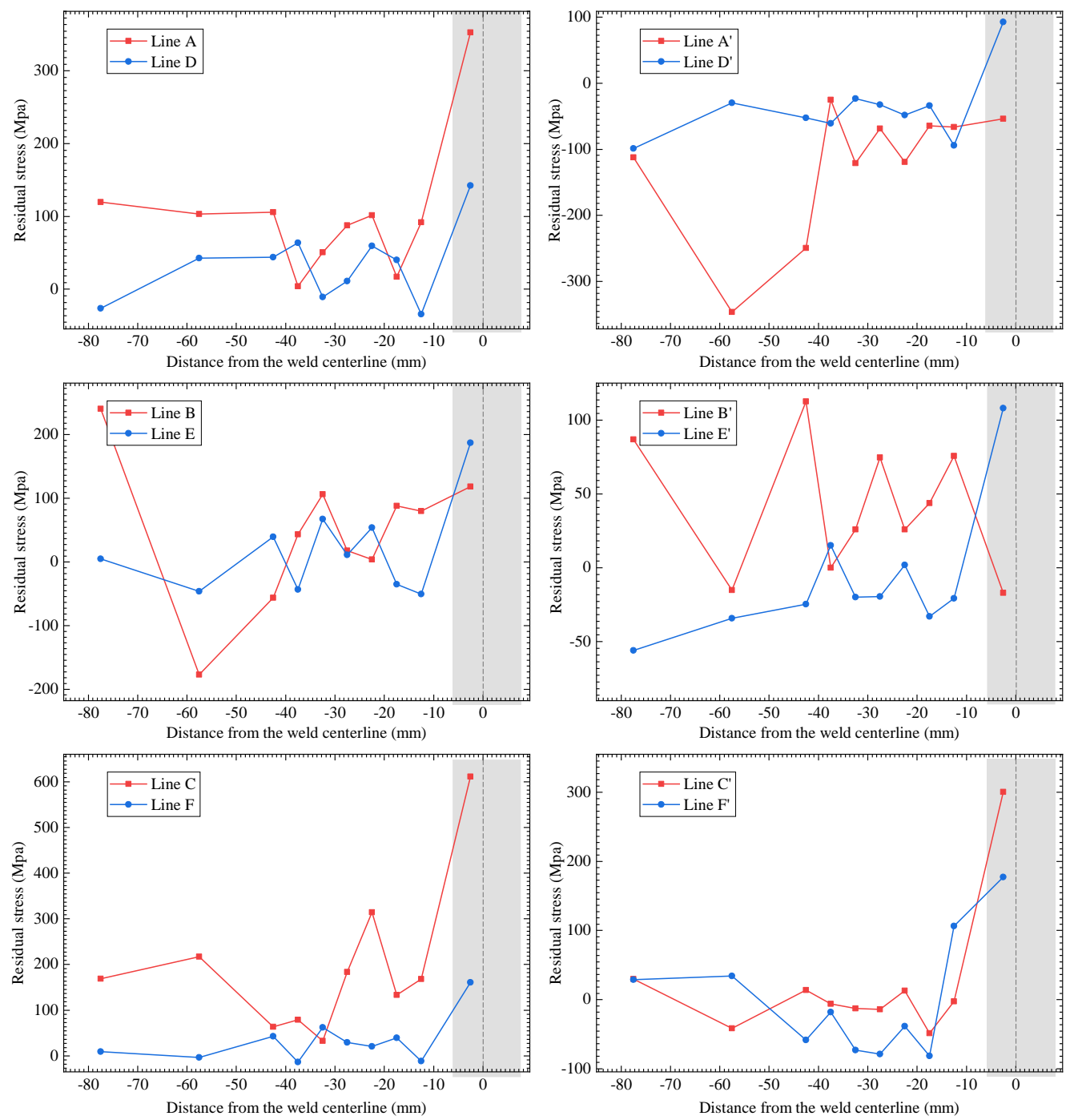

Fig. 7 WRS of different welding processes of the plates

The measurement results of the different measuring lines of the same weld are compared. In Fig. 8, the residual stress distribution of each line is irregular. The residual stress of each line is either from tensile to compressive or gradually from compressive to tensile. The measured values of the measuring points with the same distance from the weld vary significantly. The peak tensile stress of Lines $\mathrm{A}$ and $\mathrm{C}$ appear at the weld, and the tensile stress of Measuring line $\mathrm{C}$ is relatively large. The peak compressive stress of Line $\mathrm{B}$ is at $-57.5 \mathrm{~mm}$ from the centreline. In Fig. 9, the stress distribution consistency of each line is improved, and the stress values of several points located from $-10 \mathrm{~mm}$ to $-50 \mathrm{~mm}$ are basically equal. The maximum tensile stress of each line is approximately $180 \mathrm{Mpa}$ at -2.5 $\mathrm{mm}$ from the centreline. The compressive stress is small and appears at measuring line $\mathrm{E}$, which is $-50.47 \mathrm{Mpa}$. It can be seen that due to the various welding processes, the residual stress distributions of the same weld bead are different. The process stability is better in SAW than in EW. 


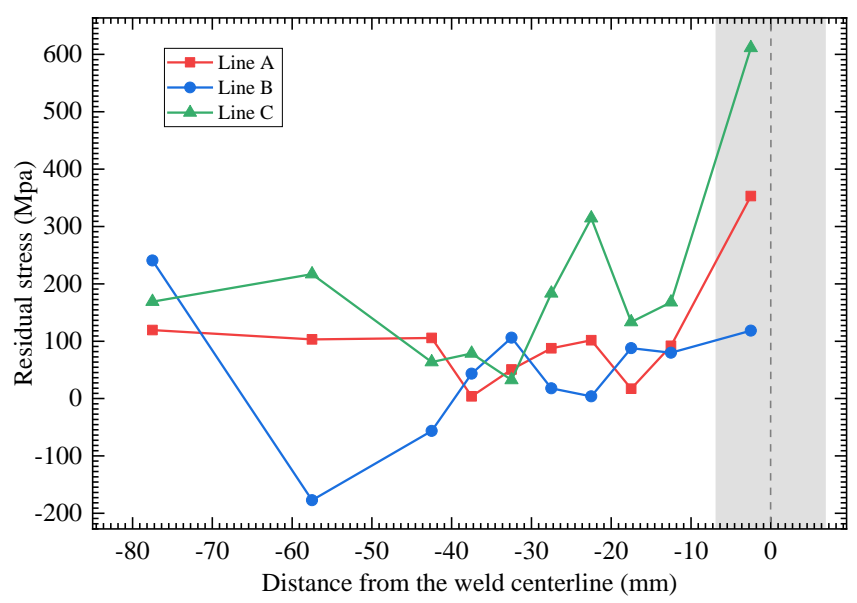

Fig. 8 WRS distribution of measuring lines A, B and C

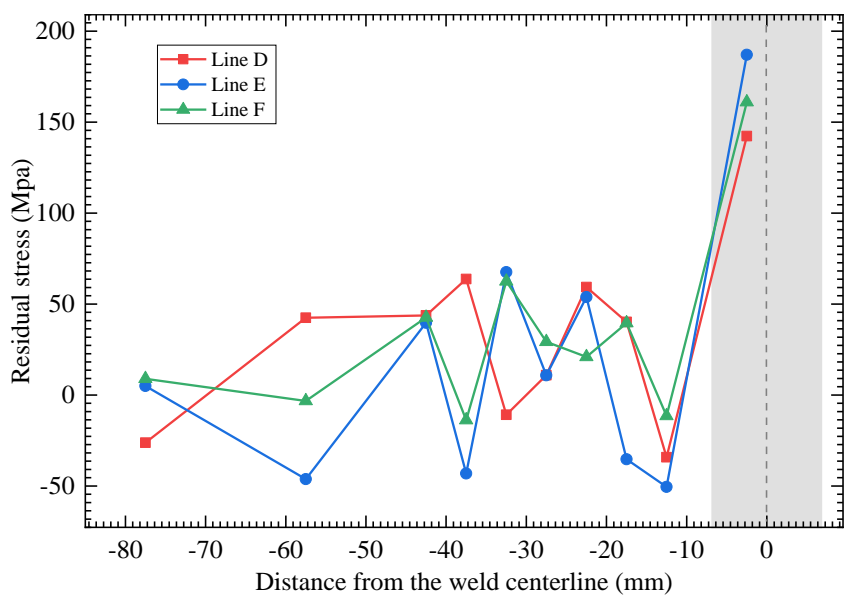

Fig. 9 The WRS distribution of measuring lines D, E and F

\subsection{Both sides of the plates}

In Fig. 10, the WRS of both sides of the plates are different. In general, the trend of residual stress change on both sides is approximately the same, and the measuring stress is higher on the top side than on the backside. This result is due to the two sides have different cooling processes during the welding process, and weld shrinkage occurs. Moreover, the possible superposition of phase transition is also an important factor that contributes to the difference. 

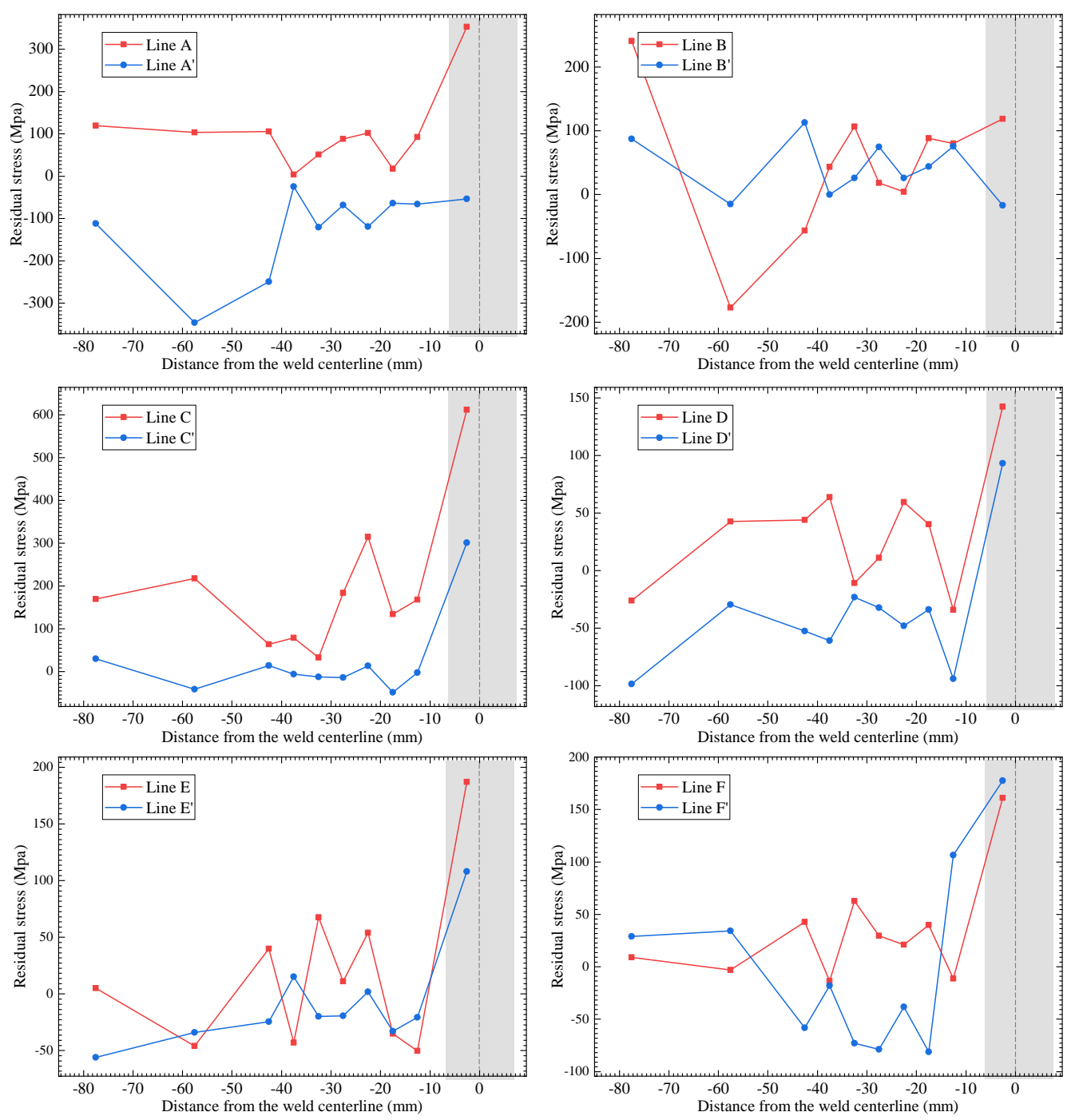

Fig. 10 WRS of different side of the plates

\subsection{Comparison of the plates and cylinder}

In Fig. 11, the WRSs are smaller in Measuring lines $\mathrm{J}$ and $\mathrm{K}$ of the circumferential weld than in the plate's Measuring line A because the weld has undergone radial shrinkage deformation, thereby releasing a portion of the stress. The stresses of Lines J and K are 91.92 and $-67.33 \mathrm{Mpa}$, correspondingly; these stress values are small because the residual stress of the circumferential weld is superimposed by two parts. Firstly, opposite thermal stresses of thermal expansion and contraction constantly exist on both sides of the cylinder considering the temperature difference between the outer and inner sides of the cylinder. Tensile stress is generated on the high-temperature side, whereas compressive stress is generated on the lowtemperature side. Secondly, concave and additional bending moments and stresses are generated on the weld and its sides due to the cooling contraction of the weld. Tensile residual stress is generated at the inner side, whereas compressive residual stress is generated on the outer side. The thickness and diameter of the cylinder are small, and the bending stress will be small or even negative. The comparison of the measuring lines of the axial weld and plate indicates that the maximum WRSs are nearly equal. The tensile stress zone of the longitudinal weld is narrow and quickly transferred to the compressive stress zone with maximum stress of $-133.52 \mathrm{Mpa}$. This result is related to the distribution of the temperature field during welding. 
The temperature gradient in the weld and its narrow region is large. Furthermore, the peak temperature away from the weld is sharply decreased, and the gradient tends to be small.
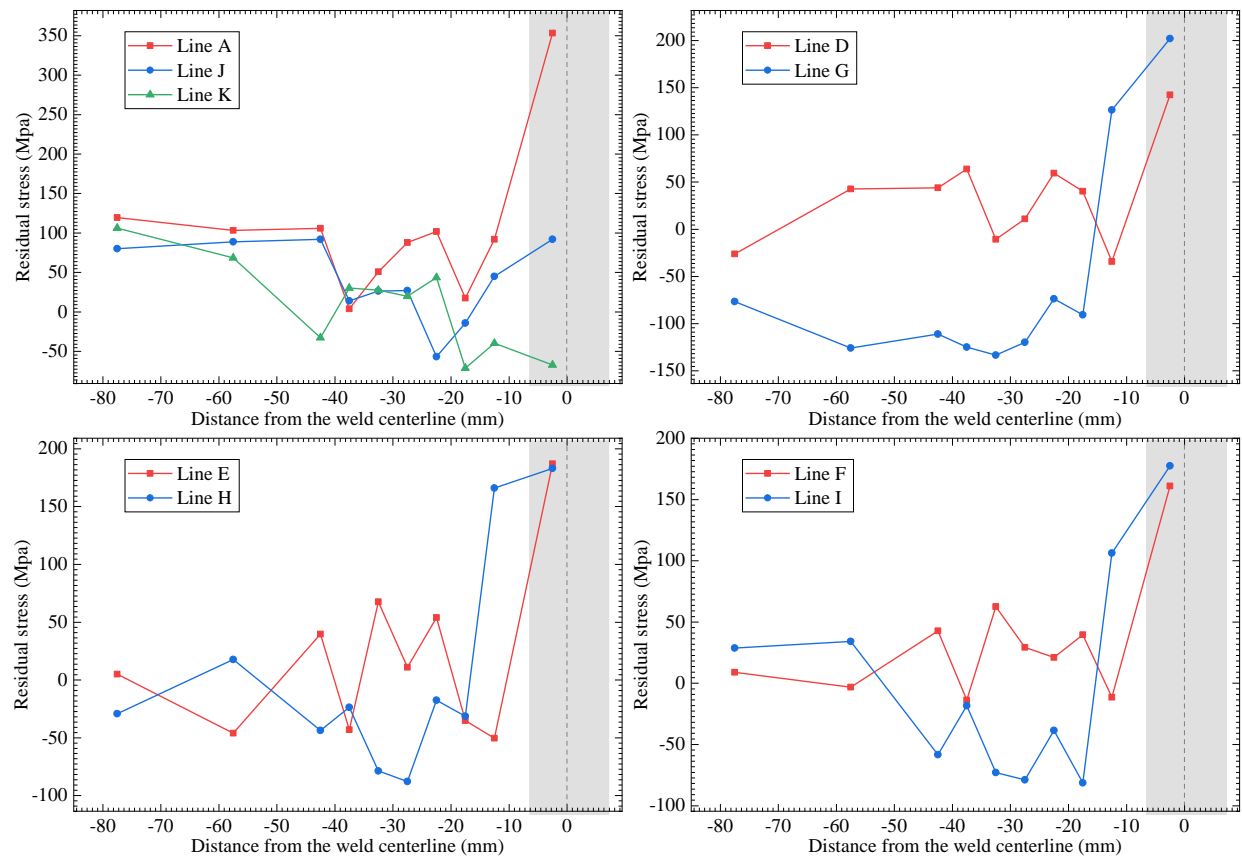

Fig. 11 WRS comparison of the plates and cylinder

\section{Conclusions}

The plates and cylinder experimental modes of high-strength shipbuilding steel are created to measure the WRS. The models are welded by EW and SAW. The WRS was measured by the instrumented indentation method.

Among the measured results, the maximum tensile stress is $611.29 \mathrm{MPa}$ which exceeds the yield stress of the material. The maximum compressive stress is $-346.43 \mathrm{Mpa}$. WRS mainly exists at the weld and heat-affected zone near the weld bead. Tensile stress is mainly generated at the weld, and compressive stress is generated away from the weld. Different welding processes will result in various forms of WRS distributions. The stress distribution of EW is minimally regular, and the process stability is better in SAW than in EW. Given the different welding and cooling processes, the WRSs on both sides of the plates are different. The measured stress is smaller in the circumferential weld than in the plates due to the shrinkage deformation of the weld of the cylinder. The longitudinal weld of the cylinder has a narrow tensile stress zone and a large gradient stress variation.

The instrumented indentation method has high accuracy and speed in measuring the residual stresses and is suitable for stress assessment at shipbuilding sites. WRS has an impact on ship performance. The measured data in this research can provide data basis for accurate prediction of ship structural safety, reliability, fatigue performance etc. According to the calculation results, corresponding process improvement measures may be taken to improve the shipbuilding quality.

\section{Acknowledgments}

The authors gratefully acknowledge the financial support of the Fund of State Key Laboratory of Ocean Engineering [GKZD010074] and Shanghai Sailing Program [18YF1411500]. 


\section{REFERENCES}

[1] Konkol PJ, Mathers JA et al (2003). Friction stir welding of HSLA-65 steel for shipbuilding. Journal of ship production 19:159-164.

[2] Suzuki S, Muraoka R et al (2004). Steel products for shipbuilding. JFE technical report 2:41-46.

[3] Chang PH, Teng TL (2004). Numerical and experimental investigations on the residual stresses of the butt-welded joints. Computational Materials Science 29:511-522. https://doi.org/10.1016/j.commatsci.2003.12.005

[4] Liu Y, Chen L (2016). The effect of weld residual stress on the free vibrational characteristics of cylindrical shell through the analytical method. Journal of Vibroengineering 18(1):334-349.

[5] Mochizuki M (2007). Control of welding residual stress for ensuring integrity against fatigue and stress-corrosion cracking. Nuclear Engineering and Design 237:107-123. https://doi.org/10.1016/j.nucengdes.2006.05.006

[6] Webster G, Ezeilo A (2001). Residual stress distributions and their influence on fatigue lifetimes. International Journal of Fatigue 23:375-383. https://doi.org/10.1016/S0142-1123(01)00133-5

[7] Yang N, Chen L et al (2016). The effect of welding residual stress on the free vibration of underwater $\begin{array}{llllll}\text { cylindrical shell. Journal of } & \text { Vibroengineering } 18 & \text { (4):2016-2030. }\end{array}$ https://doi.org/10.21595/jve.2016.16747

[8] Perić M., Tonković $\mathrm{Z}$ et al (2014). Numerical analysis and experimental investigation of welding residual stresses and distortions in a T-joint fillet weld. Materials \& Design 53:1052-1063. https://doi.org/10.1016/j.matdes.2013.08.011

[9] Liang W, Murakawa $\mathrm{H}$ et al (2015). Investigation of welding residual stress distribution in a thick-plate joint with an emphasis on the features near weld end-start. Materials \& Design 67:303-312. https://doi.org/10.1016/j.matdes.2014.11.037

[10] Deng D, Murakawa H (2008). Prediction of welding distortion and residual stress in a thin plate buttwelded joint. Computational Materials Science 43:353-365. https://doi.org/10.1016/j.commatsci.2007.12.006

[11] Deng D, Ogawa K et al (2010). Finite element analyses of residual stresses in typical welded joints used in nuclear power plants and comparisons with experiments, ASME 2010 Pressure Vessels and Piping Division/K-PVP Conference, American Society of Mechanical Engineers. pp. 885-896

[12] Lin J, Ma $\mathrm{N}$ et al (2017). Measurement of residual stress in arc welded lap joints by $\cos \alpha \mathrm{X}$-ray diffraction method. Journal of Materials Processing Technology 243:387-394. https://doi.org/10.1016/j.jmatprotec.2016.12.021

[13] Zhao D, Liu Y et al (2015). The calculation and measurement of welding residual stress for invar steel of a liquefied natural gas carrier's containment system. Journal of Ship Production and Design 31:43-48. https://doi.org/10.5957/JSPD.31.1.130048

[14] Kong F, Kovacevic R (2010). 3D finite element modeling of the thermally induced residual stress in the hybrid laser/arc welding of lap joint. Journal of Materials Processing Technology 210:941-950. https://doi.org/10.1016/j.jmatprotec.2010.02.006

[15] Chen $Z$, Chen $Z$ et al (2015). Influence of welding sequence on welding deformation and residual stress of a stiffened plate structure. Ocean Engineering 106:271-280. https://doi.org/10.1016/j.oceaneng.2015.07.013

[16] Kong F, Kovacevic R (2013). Measurement of surface residual stresses and testing mechanical properties of high-strength steel butt joints obtained by hybrid laser/gas metal arc welding. The Journal of Strain Analysis for Engineering Design 48:437-445. https://doi.org/10.1177/0309324713496085

[17] Estefen S, Gurova T et al (2010). Surface residual stress evaluation in double-electrode butt welded steel plates. Materials \& design 31:1622-1627. https://doi.org/10.1016/j.matdes.2009.08.035

[18] Fu G, Lourenco M.I et al (2014). Effect of boundary conditions on residual stress and distortion in Tjoint welds. Journal of Constructional Steel Research 102:121-135. https://doi.org/10.1016/j.jcsr.2014.07.008

[19] Fu G, Gurova $\mathrm{T}$ et al (2015). Numerical and experimental studies of residual stresses in multipass welding of high strength shipbuilding steel. Journal of Ship Research 59:133-144. https://doi.org/10.5957/JOSR.59.3.150011 
[20] Ahn, J. H., \& Kwon, D. (2001). Derivation of plastic stress-strain relationship from ball indentations: Examination of strain definition and pileup effect. Journal of Materials Research, 16(11), 3170-3178. https://doi.org/10.1557/JMR.2001.0437

[21] ISO. (2008). Metallic materials-Measurement of mechanical properties by an instrumented indentation test - Indentation tensile properties. ISO/TR 29381, Geneva, Switzerland.

[22] Tyulyukovskiy, E., \& Huber, N. (2006). Identification of viscoplastic material parameters from spherical indentation data: Part I. Neural networks. Journal of materials research, 21(3), 664-676. https://doi.org/10.1557/jmr.2006.0076

[23] Suresh, S., \& Giannakopoulos, A. E. (1998). A new method for estimating residual stresses by instrumented sharp indentation. Acta Materialia, 46(16), 5755-5767. https://doi.org/10.1016/S13596454(98)00226-2

[24] Lee, Y. H., \& Kwon, D. (2003). Measurement of residual-stress effect by nanoindentation on elastically strained (100) W. Scripta Materialia, 49(5), 459-465. https://doi.org/10.1016/S1359-6462(03)00290-2

[25] Zhao SQ (2008) Welding technology analysis of low carbon high strength steel. MW Metal Forming (10), 61-62

Submitted: $\quad$ 21.09.2018. $\quad$ Yongjin Guo

Accepted: $\quad$ 18.03.2019. $\quad$ Hongdong Wang, Corresponding author: whd302@sjtu.edu.cn Hong Yi

MOE Key Laboratory of Marine Intelligent Equipment and System, State Key Laboratory of Ocean Engineering, Shanghai Jiao Tong University, Shanghai 200240, PR China 